\title{
El enmascaramiento de la rebelión de Tupac Amaru II
}

\author{
Nombre: $\quad$ Claudia Ormeño Espinoza $(*)$ \\ Universidad: Universidad de Santiago de Chile \\ Ciudad: $\quad$ Santiago \\ País: $\quad$ Chile \\ Correo: oyemeconlosojos@gmail.com
}

\section{Resumen}

Este artículo propone un acercamiento a los movimientos insurreccionales indígenas y campesinos del siglo XVIII en la zona andina, los cuales han sido estudiados desde una perspectiva reduccionista que frecuentemente los limita a meras manifestaciones de malestar creadas por las políticas coloniales. Sin embargo, una revisión de los funcionamientos e ideologías presentes en estos movimientos, convierte al fenómeno en un objeto de estudio interesante. Debido a las condiciones impuestas por la dominación española en la América Colonial, las ideologías mesiánicas y milenaristas andinas -que funcionan como sustrato ideológico en las rebeliones y alzamientos indígenas y campesinos-, toman formas externas (por ejemplo las ideas judeocristianas del "fin del mundo") como una estrategia de enmascaramiento para poder difundir y expandir su ideología andina, sin censura ni represiones, pues ese discurso, serviría como el "disfraz" que permite su circulación en el mundo oficial y traer de vuelta así el tiempo del Inca. Esta estrategia de enmascaramiento, evidencia la apropiación de un discurso oficial, que al mismo tiempo sirve de argumento para denunciar de manera crítica las políticas y condiciones impuestas en nuestro continente desde el gran impacto que significó la Conquista.

\section{Palabras claves}

Milenarismo, mesianismo, rebelión, discurso crítico, enmascaramiento.

\footnotetext{
- La autora es Licenciada en Educación en Castellano, Tesista Magíster en Literatura Latinoamericana.
} 


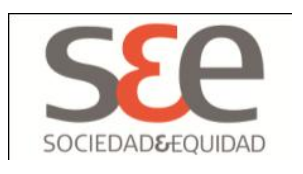

\section{The masking of the Tupac Amaru rebellion}

This article proposes an approach to indigenous and peasant revolutionary movements of the eighteenth century in the Andean region, which have been studied from a reductionist perspective that often limited to mere expressions of discomfort created by colonial policies. However, a review of the workings and ideologies present in these movements, the phenomenon becomes an object of interesting study. Due to the conditions imposed by Spanish rule in colonial America, the Andean millenarian messianic ideology, which function as substrate ideological rebellions and indigenous and peasant uprisings, taking external forms (eg, Judeo-Christian ideas of "end the world ") as a masking strategy to disseminate and expand its Andean ideology, without censorship or repression, since that speech, serve as the" disguise "that allows movement in the official world and bring back and the time of the Inca. This strategy of concealment, evidence ownership of an official discourse, which simultaneously serves as an argument for a critical report policies and conditions on our continent from the great impact that meant the conquest.

\section{Keywords}

Millennialism, messianism, rebellion, critical discourse, masking. 


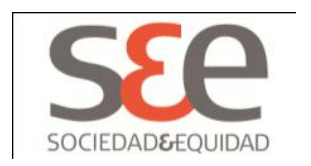

\section{Introducción}

La visión historiográfica tradicional, marcada y cegada por sus raíces etnoeurocéntricas, ha privilegiado la visión y el conocimiento de aquellos aspectos de la historia cultural de América que se relacionan con los sectores blancos, urbanos, letrados y masculinos. Producto de esta tendencia, se han restringido y mal leído innumerables procesos que forman parte del grupo marginado: indígenas, campesinos, mujeres, negros, etcétera. Es por esto que se hace necesario complementar una visión de conjunto de la realidad americana que permita releer y romper con la visión estática que ha prevalecido en los estudios de esta realidad cultural. En este sentido, se hace inevitable llevar a cabo toda una revisión de los procesos culturales de América, que desde el gran impacto que significó la Conquista, han sido modelados por los círculos de poder.

En esta oportunidad, queremos centrar la mirada en los movimientos insurreccionales indígenas y campesinos del siglo XVIII en la zona andina, puesto que se presentan como un fenómeno que pese a su gran impacto (según los datos entregados por Alberto Flores Galindo, superan los 128 sólo en este siglo), tienden a ser estudiados desde una visión paternalista. Son pocos los estudios que han sido capaces de otorgarle la importancia que tuvieron y tienen para la identidad latinoamericana ${ }^{1}$. Las explicaciones en torno a la gran proliferación de estos movimientos, tienden a ser reduccionistas, señalando que son meros mecanismos culturales para aliviar los malestares producidos por el cambio social que degradan o hacen peligrar el status del grupo campesino e indígena en el sistema económico y político del periodo. Sin embargo, una revisión de los funcionamientos e ideologías presentes en estos movimientos, convierte al fenómeno en un objeto de estudio interesante. Juan M. Ossio, precisamente apunta a esto cuando cuestiona esa visión reduccionista señalando los casos de México y Guatemala, ciudades en donde los habitantes fueron sometidos a un proceso de deprivación similar e incluso (en muchos casos) superior al andino, pero que escasearon en movimientos insurreccionales (Ossio, 1973: XXI).

La respuesta a este problema según lo planteado por Ossio, tiene que ver con la ideología mesiánica que caracteriza a estos movimientos. Esta ideología, se basa en una concepción cíclica del tiempo en donde el mundo y el orden social aparecen ordenados desde la eternidad, lo cual se ajusta a la visión milenaria de Hobsbawm, ya que el campesino andino espera que su mundo "tal cual es resurja profundamente cambiado", aunque con la participación de un Principio Mediador (Ossio, 1973: XX). Así, estos movimientos dan cuenta de un proyecto y una manifestación superior al de aliviar malestares producidos por el sistema colonial, puesto que se quiere recuperar el equilibrio perdido y "retornar al tiempo de Inca". En palabras de Ossio "el milenio en el mundo andino se presenta nada más que como la inversión simétrica del orden actual. Se trata, según se

\footnotetext{
${ }^{1}$ Me refiero a trabajos como los de Scarlet O'Phelan Godoy: Un siglo de rebeliones anticoloniales. Perú y Bolivia 1700-1783, Cusco, Perú: Centro de Estudios Rurales Andinos Bartolomé de las Casas, 1988. También las aclaraciones y planteamientos lúcidos de Juan M. Ossio (Comp.): Ideología Mesiánica del Mundo Andino. Lima: Edición de Ignacio Prado Pastor, $1^{\mathrm{a}}$ ed., 1973, entre otros autores, como Gustavo Faveron Patriau o Alberto Flores Galindo.
} 


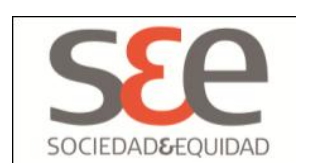

puede apreciar en Guamán Poma, que los indígenas recobren su posición "Hanan" ("Alta" con respecto a los españoles) perdida por la Conquista" (Ossio, 1973: XXIII).

Este proceso tiene una explicación que se basa en uno de los mitos más importantes de la tradición andina: el mito de Incarri. Luego del asesinato a Atahualpa, Inca rey, en 1533, la resistencia indígena se centra en la zona de Vilcabamba donde el Imperio Inca continuaba existiendo de forma independiente. Pero este, finaliza en 1572 con la muerte de Tupac Amaru I, el cual es descuartizado y sus partes enterradas en diferentes zonas del Perú, tal como ocurrió con el rey Atahualpa. Este hecho da origen al mito de Incarri (Inca rey) el cual está creciendo bajo la tierra (Pachamama) para regresar y restablecer el orden perdido en un reinado de mil años, según la visión de mundo andina ${ }^{2}$. El retorno de Túpac Amaru o la "suprema serpiente" anuncia el Pachacuti, el cataclismo que destruye y construye a la vez, en la medida que renueva y repara el caos imperante. Por eso, los nombres de los principales líderes de los movimientos insurreccionales de la zona andina no son casualidad: Túpac Amaru (Perú) y Túpac Catari (Bolivia). Túpac significa "cosa real", "suprema" y Amaru = serpiente (en quechua), Catari = serpiente (en aymara). Este mito, bajo la perspectiva eurocéntrica (judeo-cristiana) equivale al cumplimiento de las profecías que anuncian el "fin del mundo" y el inicio de otro nuevo (perfecto y eterno).

Esta equivalencia de creencias, trae consigo más de un problema, puesto que bajo la mirada eurocéntrica se tiende a pensar que por encontrar en algunos de los movimientos andinos elementos de la tradición judeo-cristiana -como las concepciones del devenir del mundo reminiscentes a las divulgadas por Joaquín de Fiore en el siglo XII europeo y difundidas por la orden franciscana en América-, estos movimientos tendrían su sustento ideológico en concepciones del mundo religioso occidental y sólo se explicarían por la influencia europea. Pero lo que esta concepción (dada por el etnocentrismo judeo-cristiano) no considera, es que estos elementos foráneos se pudieron refundir y adquirir así, un nuevo sentido de aquel que tenían en el contexto en que fueron sacados. De esta forma, al problematizar y relativizar esta verdad absoluta en torno a las ideologías de los movimientos o rebeliones indígenas y campesinas del periodo, surge una nueva interrogante: ¿por qué razón estos movimientos toman la forma externa, foránea del milenarismo y mesianismo como sustrato ideológico de sus alzamientos y no toman sus propios milenarismos y mesianismos como es el caso del mito de Incarri? La respuesta quizás puede encontrarse en la estrategia que por años ha tenido que utilizar el sujeto indígena para mantener viva su cultura y cosmovisión, sin tener que padecer los castigos por parte de la cultura dominante: la máscara y el disfraz.

Para desarrollar esta importante hipótesis y explicar de qué forma se utiliza una estrategia de enmascaramiento en dicho proceso, es necesario aclarar y dar cuenta en primer lugar de la amplitud de los conceptos de milenarismo y mesianismo, los cuales tampoco han estado exentos de lecturas limitantes que tienden a restringirlos como meras doctrinas religiosas.

\footnotetext{
${ }^{2}$ El mundo de los Inca se dividía en cinco edades o soles y cada uno de ellos tenía una duración de mil años. Según Montecinos, cada mil años moría un sol, aparecía otro nuevo y se reiniciaba el recuento de los años (Zuidema, 1973: 12).
} 


\section{s\&e \\ SOCIEDADEEQUIDAD}

\section{Milenarismo y Mesianismo en las rebeliones}

La voz "milenarismo" (también mesianismo) designa originalmente la creencia en el milenio, que para el cristiano era el periodo de mil años durante el cual Cristo encarnado reinaría en este mundo. Sin embargo, el significado del término es mucho más amplio y supera los límites de la tradición judeo-cristiana. Norman Cohn, en su texto En pos del milenio (1997) señala que el significado original de milenarismo era limitado y restringido a la cristiandad, la cual ha tenido siempre una escatología, en el sentido de una doctrina, respecto a "los tiempos finales", "los últimos días" o "el estado final del mundo". La creencia de algunos cristianos, basada en la autoridad del Libro de la Revelación, dice que Cristo, después de su Segunda Venida, establecería un reino mesiánico sobre la tierra y reinaría en ella durante mil años antes del Juicio Final. Según el Libro de la Revelación, los ciudadanos de este reino serían los mártires cristianos, quienes resucitarían para este fin mil años antes de la resurrección de los demás muertos. Cohn, señala que ya los primeros cristianos interpretaron esta parte de la profecía en un sentido más liberal que literal, equiparando a los fieles sufrientes, es decir ellos mismos, con los mártires, y esperando la Segunda Venida durante su vida mortal (Cohn, 1997: 14).

Durante el siglo XVIII apareció todavía otro tipo de escatología junto a las escatologías derivadas del libro del Apocalipsis. Joaquín de Fiore (1145-1202) fue el inventor del nuevo sistema profético, el cual iba a ser el que mayor influencia ejerciera en Europa hasta la aparición del marxismo (Cohn, 1997: 107). Según Cohn, este abad y ermitaño calabrés recibió entre 1190 y 1195, una inspiración que le pareció revelar un significado oculto de gran valor profético. Elaboró una interpretación de la historia como ascenso en tres edades sucesivas, cada una de ellas presidida por una de las personas de la Santísima Trinidad:

La primera edad era la del Padre o de la Ley; la segunda la del Hijo o del Evangelio; la tercera la del Espíritu, y ésta sería con respecto a las anteriores como la luz del día comparada con la de las estrellas y la aurora, como el ardiente estío comparado con el invierno y la primavera. La primera época había sido de temor y servidumbre, la segunda de fe y sumisión filial, la tercera sería una época de amor, alegría y libertad, en la que el conocimiento de Dios se revelaría directamente en los corazones de todos los hombres.

(Cohn, 1997: 108)

Este pensamiento, tenía implicaciones que eran potencialmente peligrosas para la estructura de la teología medieval ortodoxa. Según Cohn, su idea de una tercera edad no podía reconciliarse con la concepción agustiniana de que el reino de Dios ya se había realizado, hasta donde puede realizarse sobre la tierra, en el momento en que nació la Iglesia, y de que no puede haber ningún milenio que no sea éste (Cohn, 1997: 10). La influencia de Joaquín de Fiore puede detectarse en la filosofía y también en la dialéctica marxista. Lo que impresionó de ella, sobre todo, fue la narración de cómo y cuándo el mundo iba a sufrir su transformación última. Tal fue su impacto, que la orden franciscana adoptó esta doctrina, convirtiéndose en una de las más importantes; la 


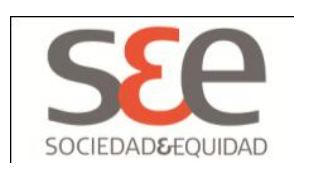

orden penetró a las universidades, buscó y obtuvo influencia, adquirió propiedades y fue una de las primeras órdenes en evangelizar a los indios de América.

En los últimos años, el término milenarismo se utiliza en un sentido mucho más amplio que el dado por la cristiandad, convirtiéndose en "una etiqueta convencional para un tipo particular de salvacionismo" (Cohn, 1997: 14). Este "salvacionismo" se refiere a que los movimientos o sectas milenaristas siempre conciben la salvación como un hecho que se manifiesta por medio de cinco aspectos. Así, este hecho debe ser:

a) colectivo, en el sentido de que debe ser disfrutado por los fieles como colectividad;

b) terrenal, en el sentido que debe realizarse en la tierra y no en un cielo fuera de este mundo;

c) inminente, en el sentido de que ha de llegar pronto y de un modo repentino;

d) total, en el sentido de que transformará completamente la vida en la tierra, de tal modo que la nueva dispensa no será una mera mejoría del presente sino la perfección;

e) milagroso, en el sentido de que debe realizarse por, o con, la ayuda de intervenciones sobrenaturales .

(Cohn, 1997: 15)

Pese a esto, Cohn, precisa que aún dentro de estos límites hay cabida para una infinita variedad, pues son innumerables los modos posibles de imaginar el Milenio y el camino que conducirá a él ${ }^{3}$. "Las actitudes de los movimientos y sectas milenaristas han oscilado entre la agresividad más violenta y el más manso pacifismo y entre la más etérea espiritualidad y el materialismo más terrenal" (Cohn, 1997: 15). Desde esta visión, los movimientos milenaristas y/o mesiánicos, pueden equivaler a grandes movimientos tales como el Barroco, que surgen en diferentes contextos tomando variadas formas y matices ${ }^{4}$. Cohn, agrega además, que la existencia de una visión de mundo religiosa tradicional que prometa una era futura de bienaventuranza para el creyente, condiciona el desarrollo del milenarismo. Cualquier humillación insólita que no pueda sobrellevarse recurriendo a una rutina institucionalizada (norma terrenal), intensifica el latente anhelo humano de salvarse de una vez del sufrimiento, lo que proporciona la oportunidad perfecta para el surgimiento de un profeta. Este "elegido" se convierte así en el portador de la

\footnotetext{
${ }^{3}$ El autor toma como ejemplo las diferencias entre los movimientos y sectas milenaristas de la Europa medieval: los llamados "espirituales franciscanos" por un lado y los desposeídos de las ciudades y los campos por otro, quines se caracterizaron por un milenarismo violento y anárquico y, a veces, revolucionario.

${ }^{4}$ Esta idea la profundiza José Antonio Maravall en La cultura del Barroco: Análisis de una estructura histórica. Barcelona: Ariel, 1990.
} 


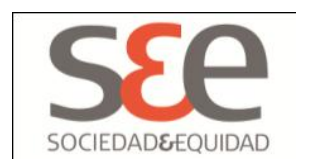

salvación colectiva, apoyándose en la promesa de eterno bienestar presente ya en la tradición popular ${ }^{5}$.

Mercedes López-Baralt en su estudio titulado El retorno del Inca rey: mito y profecía en el mundo andino, señala que el milenarismo aparece cuando las estructuras sociales se ven amenazadas desde afuera o desde dentro. Como factor externo, la aculturación parece ser el primer agente catalítico en desencadenar el mecanismo del movimiento milenarista, de ahí la definición de $\mathrm{R}$. Bastide "el mesianismo es ante todo mitología historizada, en la cual el mito de creación se transforma en un mito de Apocalipsis y el héroe civilizador se convierte en libertador" (LópezBaralt, 1989: 19). El contexto americano se presenta como un ambiente propicio para desencadenar movimientos con tales características, sobre todo el del siglo XVIII, periodo marcado por los abusos e injusticias hacia el sector indígena, el cual desde la Conquista ha debido someterse a los designios y mandatos europeos que representan la muerte, el hambre y la miseria.

\section{Reformas Borbónicas y el contexto de rebelión}

Gustavo Faverón Patriau en su libro Rebeldes, señala que el siglo XVIII encontró a España un paso más atrás de los otros imperios de Occidente, un orden mercantil distinto había sobrevenido bajo la forma de las grandes empresas holandesas y británicas en las Indias orientales. España, en cambio, sólo contaba con sus virreinatos americanos y unas rutas marítimas que la misma Corona limitaba, con afán monopólico y temor a la transformación. Sus virreinatos escapaban cada vez más de su fuerza fiscalizadora, desoyendo sus regulaciones, con frecuencia traficando con las potencias rivales y abriendo circuitos internos de negocios no previstos desde la Corte. El cambio de dinastía y el ingreso de los Borbones al poder a inicios de ese siglo, traería la promesa o la amenaza, de una serie de cambios en América:

La reafirmación del Estado se debía traducir a una hispanización mayor de la administración colonial, para rescatarla de los intereses de las oligarquías criollas; una política tributaria eficaz debía subsanar las pérdidas recientes y acrecer la recaudación en las colonias, para tranquilidad financiera de la metrópoli; una apertura de las vías comerciales debía permitir que España recibiera las ganancias virreinales de forma amplia, sin detenerse en el filtro de las corporaciones sevillanas que negaban el producto de su comercio con América y otras regiones de la península.

(Faverón Patriau, 2006: 11)

En 1740, la Corona volvió sobre un modelo de tráfico marítimo descartado en el pasado a causa de los ataques extranjeros que forzaron a la implantación de los convoyes: los navíos de registro,

\footnotetext{
${ }^{5}$ Idea tomada del texto de Mercedes López-Baralt: El retorno del Inca rey: mito y profecía en el mundo andino en donde se cita la $3^{\text {a }}$ edición de En pos del milenio de Norman Cohn del año 1970, página 42.
} 


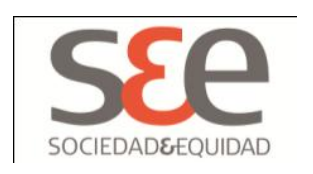

naves de circulación frecuente, que no tenían que aguardar la recolección de grandes cantidades de mercancía antes de echarse a navegar. Se amplió en número de puertos americanos desde los que podían operar, incluyendo El Callao, Perú, Veracruz y Nueva España. La medida estuvo cerca de triplicar el tráfico naviero entre España y México, y según los datos entregados por Faverón Patriau, en el virreinato peruano, elevó el comercio en tal dimensión que ocasionó un desborde de mercadería con consecuencias perversas para los indígenas "la Corona legalizó los repartimientos, es decir, la obligación de los indios de comprar mercancías arbitrariamente elegidas por los corregidores, un mecanismo de activación económica sólo posible dentro de la estructura compulsiva del mundo colonial, y que había sido detonante de incontables alzamientos" (Faverón Patriau, 2006: 12). Entre 1765 y 1778 se dio otro paso en las reformas, la Corona estableció el llamado comercio libre, que no era en verdad sino una regulación distinta de las restricciones preexistentes en el tráfico marino entre América y la península, pero el problema es que esta medida continuaba y exacerbaba los abusos en contra de los indios, puesto que el comercio libre estaba aún apoyado en la obligación de los repartos (Faverón Patriau, 2006: 13).

Por otra parte, el nuevo esquema de alcabalas, incrementa el contexto de efervescencia que se estaba produciendo. Scarlett O'Phelan Godoy en su investigación Un siglo de rebeliones anticoloniales. Perú y Bolivia 1700-1783, señala que las Reformas Borbónicas, buscaron incrementar los ingresos de la Real Hacienda. Desde 1770 en adelante, las medidas fiscales incluidas en el programa borbónico se introdujeron gradualmente en las colonias. Los pequeños productores, participaron de la expansión económica que coincidió con el repunte de la minería. Por eso se reajusta la alcabala para así incorporar a los sectores medios de la población que estaban beneficiándose de la expansión comercial. El efecto de las reformas económicas fue, de hecho, drenar el virreinato peruano de la mayor parte de sus excedentes a través de los impuestos y los monopolios estatales (O'Phelan, 1988: 177). El incremento general del impuesto de la alcabala fue más rápido en algunas provincias, debido a que con el establecimiento de las aduanas, la recaudación directa de los tributos comenzó a reemplazar al arrendamiento a terceros. Tal fue el caso de la aduana de Cochabamba, que comenzó a operar en Arque y Tapacarí en 1774, provocando protestas y disturbios. En efecto, el 2 de agosto de 1774 tuvo lugar un levantamiento en Cochabamba en protesta contra el nuevo método adoptado para la recolección de alcabalas a través de la aduana (O`Phelan, 1988: 179).

Jorge Juan y Antonio de Ulloa en su obra crítica Noticias secretas de America, entregan antecedentes de gran importancia en torno a las condiciones en que vivían los indios, sobre todo de la zona andina. Este escrito representa una de las fuentes más fidedignas para tratar este proceso, ya que sus autores fueron enviados especialmente desde España para entregar antecedentes al rey sobre los procedimientos y acciones que se llevaban a cabo en ese momento en América por parte de corregidores y gobernantes. Jorge Juan y Antonio de Ulloa dan cuenta en sus escritos de una conciencia ilustrada, más abierta y libre de la corrupción que manejaba a los gobernantes del continente. Sus escritos acusan el trato vejatorio hacia los indios por parte de sus gobernantes: 


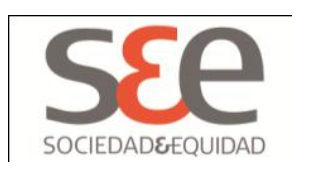

La tiranía que experimentan los indios de la insaciable hambre de riquezas que llevan a las Indias los que van a gobernarlos, y como éstos no tengan otro arbitrio para conseguirlo que el de hostilizar a los indios de cuantos modos puede suministrarles la malicia, no dejan ninguno por planificar, y combatiéndolos por todas partes, con crueldad exigen de ellos más de los que pudieran sacar de los propios esclavos.

(Juan y Ulloa, 1991: 232)

La distancia entre la metrópoli y las colonias americanas, permitía a los corregidores vivir en plena libertad para enriquecerse y abusar de los indios. Los pagos de tributos, la violencia del trabajo forzado, dan cuenta del nivel de corrupción que se vivía en las lejanías del continente americano. Mientras España vivía una cultura llustrada y se empapaba de sus postulados de libertad, autonomía y autogobierno; América parecía retroceder a una época de esclavitud y martirio, concretamente entre sus gobernantes. No bastando con los desajustes y tratos vejatorios del sector político y/o económico hacia los habitantes de las colonias, los indios padecen y son castigados también, por quienes deberían darles alivio y consuelo: los sacerdotes. Los curas "que debiendo ser sus padres espirituales y sus defensores contra las sinrazones de los corregidores, puestos de conformidad con éstos, se emulan a sacar el usufructo en competencia, a costa de sangre y del sudor de tan mísera y desdichada gente, a quien faltando el pan para sustentarse se sobran riquezas para engrandecer a otros" (Juan y Ulloa, 1991: 265-266)

Uno de los más horrendos sistemas de trabajo es el conocido como la mita. Esta consiste en el trabajo forzado de los indios en talleres o minas para enriquecer a los corregidores o hacendados:

Todos los pueblos deben dar a las haciendas de su pertenencia, para que se trabajen, un número determinado de indios, según su erección; y los mismo a las minas cuando, habiéndolas registrado sus dueños, han conseguido que se les conceda mita para hacer sus labores con más conveniencias. Esos indios deberían hacer mita en tiempo de un año, y concluido, restituirse a sus pueblos, porque yendo en su lugar otros a mudarlos, deberían quedar libres hasta que les volviera a tocar el turno. Pero esta formalidad, aunque bien dispuesta por las leyes, no se guarda ya, y así, lo mismo es para los indios el trabajar en mita para el amo de la mina o hacienda, que trabajar de libres para utilidad del corregidor, pues de ambos modos les es igual la pensión.

(Juan y Ulloa, 1991: 294-295)

Todos los corregimientos de la provincia de Quito, y los demás que siguen en las otras provincias del Perú hacia el sur y son de serranía, tenían el sistema de la mita. No son sólo los indios mitayos los que se empleaban en el trabajo de las haciendas, sino también sus mujeres y los hijos, pero no ganaban más que la ganancia que le correspondía al marido por la mita. Además, estos indios 


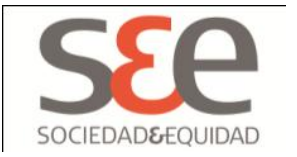

debían pagar ocho pesos de tributo cada año, así contado los 18 que gana, le quedan sólo 10, y rebajando de éstos el costo de un capisayo, que consiste en tres varas de jerga, a razón de a seis reales, les quedaban libres siete pesos y seis reales, con los cuales se ha de mantener él, su mujer y sus hijos (Juan y Ulloa, 1991: 296). Además, en épocas en que el maíz subía (tres o cuatro pesos), todos los frutos se aumentan en proporción, pero no así el salario de los mitayos, lo que propiciaba endeudamientos con los corregidores o hacendados, teniéndoles que pagar con trabajo, terminando endeudado para toda la vida.

También funcionaban los obrajes en donde "se juntan todos los colmos de la infelicidad y se encuentran las mayores lástimas que puede producir la impiedad" en palabras de Jorge Juan y Antonio de Ulloa. Los obrajes son las fábricas en donde se tejían los paños, bayetas, sargas y cosas de lana, que en todos los reinos del Perú se denominaban con la voz ropa de la tierra. Jorge Juan y Antonio de Ulloa, definen los obrajes de la siguiente manera:

Para formar un perfecto juicio de los que son los obrajes, es preciso considerarlos como una galera que nunca cesa de navegar y continuamente rema en calma, alejándose tanto el puerto que no se consigue nunca llegar a él, aunque su gente trabaja sin cesar con el fin de tener algún descanso (...) Empieza, pues, el trabajo de los obrajes antes que aclare el día, a cuya hora acude cada indio a la pieza que le corresponde, según su ejercicio, y en ella se les reparten las tareas que les pertenecen; pero luego que se concluye esta diligencia, cierra las puertas el maestro de obraje y los deja encarcelados en ella. Al medio día abre para que las mujeres de cada uno les entren la pobre y corta comida con que se han de sustentar, lo cual dura muy poco tiempo, y vuelven a quedar encerrados; a la noche, cuando ya la oscuridad no da lugar a que puedan trabajar, entra el maestro de obraje a recoger las tareas.

(Juan y Ulloa, 1991: 303).

Aquellos que no han podido concluir sus tareas son fuertemente castigados y azotados y vueltos a encerrar como castigo en la misma pieza o los ponen en la que sirve de prisión, porque pese a que toda la fábrica lo es, tienen dispuestas habitaciones para los castigos. Esto, en palabras de Juan y Ulloa, se ejecutaba cotidianamente, pero el castigo no servía de indulto para dispensarles la satisfacción de la deuda, pues eran obligados a cumplirlas a fin del año. Y así, se acrecienta, sucesivamente, cada vez más, la deuda, convirtiéndolos una vez más, en eternos esclavos.

Scarlett O'Phelan, también entrega antecedentes sobre los levantamientos en obrajes, destacando dos importantes: en 1765 y 1774 Pichuichuro y Cacamarca, respectivamente (Alto Perú). En ellos los trabajadores salieron a matar a sus mayordomos y mandones. Las declaraciones que recoge la autora, sobre los testigos de los levantamientos, subrayan el hecho de que fueron los mayordomos quienes abrieron fuego primero a través de las rendijas de la 


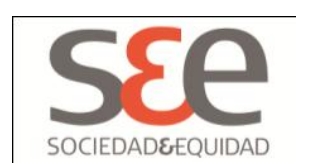

puerta matando a tres trabajadores. Instaurado el orden fueron sometidos a un interrogatorio señalando que "no tenían cosa ninguna que alegar porque ellos trabajaban con toda voluntad". Sin embargo, señala la autora, la impresión que se obtiene de sus declaraciones es que se encontraban resignados a su situación, mas no del todo convencidos que no hubiese una mejor alternativa para ellos. Sus intentos de fuga y de revuelta son claros signos de su disgusto con la administración y con el régimen productivo del obraje ( O`Phelan, 1988: 151-152).

Luego de esto, los planteamientos de Cohn adquieren sentido, puesto el contexto de "humillación insólita" al que apela en su texto, sin duda se da en las colonias americanas del siglo XVIII. El trato era tan inhumano que ya no podía ser solucionado por instituciones terrenales, ya que estas estaban corrompidas. Sacerdotes, corregidores y hacendados, representantes de los diferentes organismos de poder del sistema colonial, tenían las mismas prácticas en lo que respecta a los indios: abusar de ellos brutalmente para enriquecerse.

Por otra parte, la Colonia había sido escenario en el XVIII para la emergencia de una nueva clase social nativa, la de los indios acaudalados por el comercio, caciques o jefes que reclamaban un poder basado ya no sólo en la posición de sus antepasados en la memoria social, sino también en su capacidad económica. Así, mientras las masas indígenas sufrían con los repartimientos y el trabajo forzado (mita y obrajes), los jefes indios vivían con obstáculos que la Corona ponía a sus actividades comerciales. Este panorama o contexto de represión, de humillación insólita, fue detonante para movimientos de subversión que abarcaron sobre todo, el área andina. Así, lo señala Nelson Osorio Tejeda en un estudio enfocado a la relectura de este proceso que ha sido marginado o relegado:

En toda el área andina de esos años se estaban dando alzamientos indígenas y campesinos que se traducían en represiones, muertes y una permanente inestabilidad de la vida social, política y administrativa de las sociedades coloniales. Según Scarlett O’Phelan, por ejemplo, sólo en el territorio que actualmente corresponde a Perú y Bolivia, durante ese siglo se registraron unos 140 alzamientos indígenas y campesinos contra las autoridades dominantes; en un trabajo anterior, la misma autora había hecho un prolijo recuento de las zonas rebeldes en el Virreinato durante el siglo XVIII, y constatado el hecho de que "la historiografía tradicional se había basado en fuentes secundarias, como las Memorias de los Virreyes y no con el tratamiento directo de los manuscritos y autos judiciales, con lo cual se había falseado la historia", puesto que "a los virreyes no les convenía sacar a relucir en los documentos oficiales las convulsiones de la población autóctona durante sus periodos de gobierno"

(Osorio, 2008: 2) 


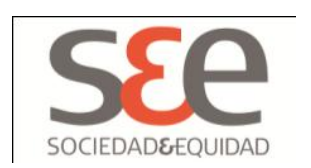

Estos alzamientos, se articularon en dos clases de discursos de resistencia. Faverón Patriau, señala que entre los pueblos nacieron discursos sustentados en sus tradiciones, que habían subsistido a la aculturación o se habían gestado en la transculturación, y que se oponían a la represión colonial en grados distintos. Entre los nativos comerciantes, hacendados o empresarios, unas veces indios y otras mestizos, apareció otra clase de discurso, sostenido quizá en idénticas fuentes, pero tendiente también a apoyarse en nociones occidentales (las ideas libertarias de la llustración) o en razones de igualdad comercial, como el derecho a producir y lucrar en las mismas condiciones que los españoles (Faverón Patriau, 2006: 15). Pero lo importante, es que ambas clases de discursos tenían un objetivo central: proponer la ilegitimidad del gobierno hispano en tierras americanas, y podían fundirse en acciones comunes: rebeliones, alzamientos, sublevaciones.

Si bien hubo numerosos alzamientos indígenas y campesinos en ese momento, pocos desarrollaron rasgos mesiánicos y se concretaron en ideologías de gran valor político-cultural. En 1780 la revolución encabezada por Tupac Amaru II fue el intento más ambicioso de convertir a la utopía andina en un programa político. El levantamiento encabezado por Túpac Amaru había sido en el territorio del virreinato peruano y sus golpes mayores ocurrirían cuando los coroneles rebeldes se trasladaran al Alto Perú (Bolivia) para unir sus fuerzas con la de los aymaras dirigidos por Túpac Catari desencadenando así la llamada "gran rebelión de los Andes".

\section{La gran rebelión de los Andes y su estrategia de ocultamiento}

Al igual que en el contexto americano, el virreinato peruano, se encontraba inmerso en una crisis económica "las minas de Huancavelica rendían menos cada vez, mucho menos que las novohispanas y las del Potosí, aunque no estaban en declive, sí demandaban gran esfuerzo de administración y provocaban el riesgo constante de un alzamiento de indios" (Faverón Patriau, 2006: 165). Así como en todo el continente, los nativos eran forzados a trabajar por el sistema de trabajo obligatorio (mita) o bien en los obrajes. El virreinato estaba organizado de tal forma que sobre ciertos funcionarios, los corregidores, recaían funciones de recaudación tributaria, decisión judicial y gobierno político, de modo que cualquier querella motivada por su actuación financiera, comercial o ejecutiva iba a dar en manos de ellos mismos, que se convertían en jueces y partes. También en el Alto Perú, que las reformas borbónicas hicieron pasar al campo administrativo del Virreinato del Río de la Plata, la situación era la misma, y los errores de la Corona en su afán recaudador, similares (Faverón Patriau, 2006: 168).

Historiadores bolivianos como Carlos Mesa, sostienen que Tomás Catari (Túpac Catari) no sólo tenía contactos con Túpac Amaru, sino que al ver las injusticias y los cambios de corregidores en sucesores aún más corruptos, lo incitaron a redoblar su correspondencia e incitar al cacique peruano al estallido de rebelión. Otros como Scarlet O'Phelan, quien descree tales teorías y se refiere a ambos levantamientos como paralelos, aunque propiciados por similares circunstancias (Faverón Patriau, 2006: 172).

El 4 de noviembre de 1780, luego de una celebración, el corregidor Antonio Juan de Arriaga y Gurbista, fue capturado por los hombres del cacique Túpac Amaru y fue ejecutado como simbolizando el inicio del fin de las injusticias. José Gabriel Condorcanqui Túpac Amaru, conocido 


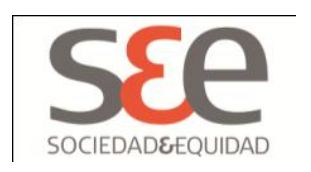

por al historia como Túpac Amaru II para diferenciarlo del padre de su tatarabuela, Felipe Túpac Amaru (el último de los incas de Vilcabamba, descuartizado al igual que Atahualpa en la Plaza Mayor del Cusco en 1572) era un noble, pero también comerciante. Desde los 12 años, había asistido al colegio para caciques e indios nobles llamado San Francisco de Borja de la orden jesuita. Hablaba y escribía en español, dominaba el quechua y leía en latín. Túpac Amaru II representaba al sector noble de la población indígena, que como señalaba, estaba igualmente descontenta con las imposiciones europeas. Su organización alcanzó límites insospechados y provocó serios desajustes en la estructura del sistema colonial.

La trascendencia de este movimiento, se debe principalmente a que funcionaba en él una ideología mesiánica que apelaba al retorno del "tiempo del Inca", idea fundada en uno de los mitos más importantes de la zona andina: Incarri. El mito fusiona la muerte de dos importantes líderes de la cultura incaica: Atahualpa y Túpac Amaru, asesinados y descuartizados frente a la plaza pública en 1533 y 1572, respectivamente. El mito cuenta que en medio de la muerte inminente de Atahualpa, este señala a sus seguidores que no morirá y volverá en forma de serpiente a reinar otra vez el imperio que ha sido desbaratado. Como señalábamos anteriormente, luego de la muerte del rey, la resistencia indígena se centra en al zona de Vilcabamba, teniendo como líder a Túpac Amaru, quien al igual que su antecesor, muere decapitado y sus partes son repartidas por todo el Perú. Sin duda la decapitación es una metáfora de desarticulación, tal como lo señala Mercedes López Baralt "la cabeza del Inca fue arrancada de su cuerpo, así como las estructuras sociales incaicas fueron socavadas por la Conquista. El pueblo andino perdió su cabeza o líder político y religioso" (López-Baralt, 1989: 40).

Así, el nombre que adopta José Gabriel Condorcanqui no es inocente, este cacique es conocedor de la cultura de sus ancestros y conoce a fondo lo que este mito significa para el pueblo: una esperanza de salvación. Como señala Ossio, el regreso al tiempo del Inca que propone el mito de Incarri, no puede confundirse con un deseo de restaurar el tiempo histórico. En una sociedad en la que predomina la transmisión oral de la cultura, el presente refunde constantemente el pasado y por lo tanto no pueden separarse el uno del otro. Así, para los hablantes del quechua, los cuales conciben el milenio en términos de una inversión simétrica del caos presente, el Inca es una categoría mítica del orden cósmico. En tanto héroe mesiánico, Incarri no es un dios del presente, sino de un pasado que es futuro. De esta forma, el Mesías es Incarri y el milenio (edades o soles) es el Pachacuti, cataclismo que viene a restaurar el orden.

Pese a esto, existen variados estudios que reducen este movimiento a la influencia de las concepciones del fin del mundo de Joaquín de Fiore, pero como ya señalaba, esta idea milenarista sólo forma parte de innumerables movimientos de esas características. Lo que ocurre es que se ha hecho una mala lectura del proceso producto de la visión totalizante eurocéntrica. Es cierto que la ideología mesiánica de la gran rebelión de los andes se acerca a las concepciones del devenir del mundo planteadas por Joaquín de Fiore; de hecho, las etapas concretadas en las personas de la Santísima Trinidad, también pueden apreciarse en la ideología andina, encarnadas en las edades o soles. Según R. T. Zuidema "El mundo de los Inca se dividía en cinco edades o soles y cada uno de ellos tenía una duración de mil años. Según Montecinos, cada mil años moría 


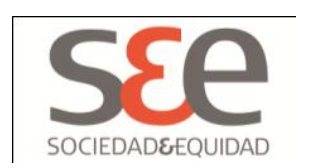

un sol, aparecía otro nuevo y se reiniciaba el recuento de los años" (Zuidema, 1973: 12). Esto quiere decir que la concepción de milenio también estaba. El problema es que la presencia de elementos de la tradición judeo-cristiana confunde a quienes no pueden ver desde otra perspectiva este proceso. Lo que ocurre, en definitiva, es que estos elementos funcionaron como un disfraz para ocultar el verdadero trasfondo de la utopía andina. La máscara, el disfraz ha servido para mantener en la memoria lo que les fue arrebatado.

La máscara, en su definición más convencional, manifiesta una cobertura, un encubrimiento, que provoca para quien la usa un cambio de identidad diferente a la propia. Según la definición que nos entrega el diccionario de la Real Academia Española, la máscara es una "figura que representa un rostro humano, de animal o puramente imaginario, con la que una persona puede cubrirse la cara para no ser reconocida, tomar el aspecto de otra o practicar ciertas actividades escénicas o rituales". La máscara disfraza, oculta y recrea otra identidad. Cuando se la está usando, hay una pérdida de la personalidad previa y se adquiere una nueva. Esta simulación e invención de la identidad y de la personalidad, se exteriorizan en el cambio de apariencia, en la pretensión de una falsa condición. Un ejemplo de ocultamiento (como estrategia) es el Taki Onqoy, danza o puesta teatral de la zona andina que posee muchos personajes con nombres cristianos, de vírgenes y santos, lo cual lo mantuvo a salvo de las censuras religiosas, pero lo que el trasfondo de éste quería plantear, era que al Dios cristiano se le estaba terminando su periodo de incumbencia y les tocaba a las huacas el turno para recrear el mundo. Algo similar ocurre con este movimiento, que en la superficie toma la forma foránea del milenarismo, pero que en su trasfondo oculta una tradición de salvación, llamando al Pachacuti "juicio final" a Incarri "Mesías" y a las edades o soles "Milenios". Tal como en el Taki Onqoy, este movimiento mesiánico oculta su trasfondo más sagrado para poder vehiculizar su ideología en medio de un contexto represor. La gran expansión del movimiento se debe precisamente a su difusión, pero jamás hubiera sido posible sin un disfraz que pudiera ocultar su verdadero trasfondo.

Si Túpac Amaru logró impactar a sus seguidores fue precisamente porque manejó un lenguaje simbólico que les era común y que contaba con una larga tradición en el mundo andino. Como Ossio muy bien lo señala, el uso de este lenguaje se revela en el mismo seudónimo que escogió el líder: Túpac Amaru (Túpac = cosa real; Amaru = Serpiente). Este hecho ha sido considerado por muchos como una excusa de José Gabriel Condorcanqui para demostrar su filiación con el último Inca Túpac Amaru I y dar legitimidad a su sucesión imperial incaica. Otros, como Ossio han restado importancia a este hecho, precisamente porque el gran líder de esta rebelión en el altiplano, que al parecer no descendía de ningún Inca, Tomás Catari, ostentó el equivalente aymara del apodo de José Gabriel Condorcanqui: Túpac Catari (Túpac = cosa real; Catari = serpiente en aymara). La identificación con la serpiente se debe también a una tradición andina, ya que la serpiente es una divinidad ctónica (subterránea). Ossio, explica este hecho señalando que "con la Conquista, el orden del mundo se invierte (mundo al revés como tantas veces repite Guamán Poma) y el Inca pasa a reinar en las sombras, en el mundo subterráneo, en la morada de la serpiente. Identificándose pues con el Amaru, estos personajes reafirmaban la nueva condición existencial del hombre andino y de la cual ellos los liberarían" (Ossio, 1973: XXVI). 


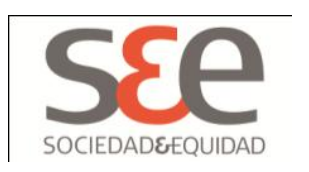

En un inicio, señalábamos que en otras zonas como México o Guatemala, las condiciones impuestas por los aparatos de poder eran igual o más fuertes que en la zona andina, pero lo que diferencia a esta rebelión de otros alzamientos, es que no se espera alcanzar esta liberación con meras reformas parciales, sino que Túpac Amaru promete a sus seguidores que aquellos que mueran bajo sus órdenes en esa guerra, tendrán la seguridad que resucitarán después de que se haya finalizado, y que disfrutarán las felicidades, y las riquezas de que están indebidamente despojados, es decir el mundo recobrará la posición que antes tuvo (Ossio, 1973: XXVI).

En este discurso, podemos ver como funciona la máscara y la estrategia de apropiación de un discurso oficial, como lo es el de la tradición judeo-cristiana. Asumir como estructura aparente las concepciones del "fin del mundo" cristiano, no sólo permite la tranquilidad para hacer circular un sustrato ideológico de guerra, sino que al mismo tiempo se intenta vengar con la misma cultura impuesta, las acciones horrendas de los funcionarios coloniales en América. Vimos como las concepciones de Joaquín de Fiore se presentaban de forma transgresora para cierto sector ortodoxo de la Iglesia, precisamente porque el milenio, el "juicio final" sería pagado o llevado a cabo en la tierra, durante su estadía en ella. De esta manera, todos aquellos que creen salvarse en "la otra vida" estarían condenados primero a pagar sus pecados en tierra, pecados como los que los corregidores les hacían a los campesinos andinos.

Así, la máscara se presenta como una doble posibilidad: encubrir un discurso sobre la memoria oral y castigar al mismo tiempo -mediante los mismos códigos religiosos y culturales impuestos-, a quienes por décadas los han mantenido en el silencio y la humillación. Esta estrategia de enmascaramiento, parece reflejar una identidad latinoamericana que se funda en la apropiación de los discursos impuestos para vengar las injusticias. Tal como lo hizo Calibán, los rebeldes del XVIII andino utilizan el propio lenguaje impuesto para responderle a su amo y maldecirlo. Calibán elabora un discurso de apropiación, de resistencia, validado por la misma cultura del dominador: "Próspero invadió las islas, mató a nuestros ancestros, esclavizó a Calibán y le enseñó su idioma para entenderse con él: ¿Qué otra cosa puede hacer Calibán sino utilizar ese mismo idioma para maldecir, para desear que caiga sobre él la «roja plaga»?"(2000: 25-26) ${ }^{6}$. No conozco otra metáfora más acertada para retratar este gran proceso cultural.

\footnotetext{
${ }^{6}$ Ver artículo de Roberto Fernández Retamar: “Todo Calibán”, Casa de las Américas, No. 68 (septiembreoctubre de 1971)
} 


\section{SEe}

\section{Referencias Bibliográficas:}

Cohn, Norman (1997) En pos del Milenio. Revolucionarios milenaristas y anarquistas místicos de la Edad Media [1957]. Madrid: Alianza Editorial.

Faverón Patriau, Gustavo (1987) Rebeldes. Sublevaciones indígenas y naciones emergentes en Hispanoamérica en el siglo XVIII. Madrid: Editorial Tecnos, 2006.

Flores Galindo, Alberto. (1987) Buscando un inca: identidad y utopía en los Andes. Lima: Instituto de Apoyo Agrario.

Juan, Jorge y Ulloa, Antonio (1991) Noticias secretas de América. Madrid: Ediciones Historia 16.

López-Baralt, Mercedes (1989) El retorno del Inca rey: mito y profecía en el mundo andino. La Paz: Hisbol.

O'Phelan Godoy, Scarlett (1988) Un siglo de rebeliones anticoloniales. Perú y Bolivia 1700-1783. Cusco: Centro de Estudios Rurales Andinos Bartolomé de las Casas.

Ossio, Juan M (Comp.) (1973) Ideología Mesiánica del Mundo Andino. Lima: Edición de Ignacio Prado Pastor.

Osorio, Nelson (2000) Consideraciones preliminares para el estudio del siglo XVIII en el mundo andino. Revista de Crítica Literaria Latinoamericana año XXXIV № 67. Lima: Manuscrito original: 1-20. 